\title{
Harnessing Innovative Technologies to Advance Children's Mental Health: Behavioral Parent Training As an Example
}

\author{
Deborah J. Jones ${ }^{\mathrm{a}}$, Rex Forehand ${ }^{\mathrm{b}}$, Jessica Cuellara, Carlye Kincaid ${ }^{\mathrm{a}}$, Justin Parent ${ }^{\mathrm{b}}$, \\ Nicole Fenton ${ }^{\mathrm{a}}$, and Nada Goodrum ${ }^{\mathrm{a}}$ \\ aUniversity of North Carolina at Chapel Hill, Department of Psychology, CB \#3270 Davie Hall, \\ Chapel Hill, NC 27599 \\ bUniversity of Vermont, Department of Psychology, John Dewey Hall, Rm 246, 2 Colchester \\ Avenue, Burlington, VT 05405
}

\begin{abstract}
Disruptive behaviors of childhood are among the most common reasons for referral of children to mental health professionals. Behavioral parent training (BPT) is the most efficacious intervention for these problem behaviors, yet BPT is substantially underutilized beyond university research and clinic settings. With the aim of addressing this research-to-practice gap, this article highlights the considerable, but largely unrealized, potential for technology to overcome the two most pressing challenges hindering the diffusion of BPT: (1). The dearth of BPT training and supervision opportunities for therapists who work with families of children with disruptive behaviors and; (2). The failure to engage and retain families in BPT services when services are available. To this end, this review presents a theoretical framework to guide technological innovations in BPT and highlights examples of how technology is currently being harnessed to overcome these challenges. This review also discusses recommendations for using technology as a delivery vehicle to further advance the field of BPT and the potential implications of technological innovations in BPT for other areas of children's mental health are discussed.
\end{abstract}

\section{Keywords}

Behavioral Parent Training; Technology; Diffusion; Disruptive Behaviors

The prevalence of mental disorders among youth worldwide is estimated to be $20 \%$ (World Health Organization, 2001). In the U.S. alone, one-fifth of children, up to 15 million, have a diagnosable disorder (Burns, Hogwood, \& Mrazek, 1999; Kazak et al., 2010). Disorders of childhood affect a wide range of youth functioning, including family and peer relationships, as well as academic performance and persist into adolescence and adulthood, exacerbating the risks for individual disability and impairment (see Costello, Foley, \& Angold, 2006; Fleitlich \& Goodman, 2001; Graeff-Martins et al., 2008, for reviews). In addition to the psychosocial costs, rates of childhood disorders fail to reflect the far-reaching economic

\footnotetext{
(C) 2012 Elsevier Ltd. All rights reserved.

Correspondence regarding this article should be directed to Deborah J. Jones, Department of Psychology, UNC Chapel Hill, CB \#3270, Chapel Hill, NC 27599-3270, djjones@email.unc.edu.

Publisher's Disclaimer: This is a PDF file of an unedited manuscript that has been accepted for publication. As a service to our customers we are providing this early version of the manuscript. The manuscript will undergo copyediting, typesetting, and review of the resulting proof before it is published in its final citable form. Please note that during the production process errors may be discovered which could affect the content, and all legal disclaimers that apply to the journal pertain.
} 
effects for families and society. For example, annual treatment costs for children in the U.S. alone are estimated to be more than $\$ 11$ billion dollars (Eyberg, Nelson, \& Boggs, 2008).

Given the prevalence, wide-ranging consequences, and costs associated with childhood disorders, increasing the availability and utilization of evidence-based interventions is a critical public health concern (Graeff-Martins et al., 2008). Yet, the provision of services for children's mental health has been recognized as at least "problematic" (Kazak et al., 2010, p. 85 ), with some noting that the failure to more adequately respond to the mental health needs of children and adolescents will result in "disability and suffering, reduce the ability to achieve health goals, and undermine the capacity for countries to be productive in an increasingly competitive world" (Belfer \& Saxena, 2006, p. 552). Accordingly, the transfer of evidence-based interventions from the university clinic and research setting to community-based practice has been identified as a public health priority (National Advisory Mental Health Council, 2001). To this end, leaders in mental health have called for a paradigm shift in clinical services and highlight that technology is at the forefront of this shift (Aguilera \& Muench, 2012; Kazdin \& Blasé, 2011).

Building upon the broader recognition that technology has the potential to change the landscape of mental health service research and delivery, this article highlights the capacity for technology to address the obstacles limiting the reach of one evidence-based treatment in particular, behavioral parent training (BPT) for childhood disruptive behavior disorders (DBDs). There are four primary reasons for our choice to focus on this intervention approach. First, disruptive behaviors (e.g., noncompliance, defiance, aggression) are among the most common reasons children are referred to mental health care (e.g., Egger \& Angold, 2006; Lundahl, Risser, \& Lovejoy, 2006; Zisser \& Eyberg, 2010). For example, in their epidemiological review of childhood mental disorders, Marikangas, Nakamura, and Kessler (2009) reported the 12-month prevalence of DBDs worldwide is second only to anxiety disorders in children and adolescents (followed by mood and substance use disorders). Accordingly, DBDs present challenges for both families and society, challenges that highlight the critical public health impact of increasing the availability of early intervention programs and engaging and retaining families in those programs.

In addition, there are multiple BPT programs for children with DBDs, each rooted in a common theoretical foundation and, in turn, a common treatment approach (e.g., Galbraith et al., 2009; Kelly, Buehlman, \& Caldwell, 2000; McKleroy et al., 2006). The early starter model (similar models include the cascade model or childhood onset type) proposes that parenting behaviors play a key role in propelling a child toward the initiation of disruptive behaviors and the escalation to DBDs, including oppositional defiant disorder and conduct disorder, as well as their correlates (e.g. risk behaviors) (see Dodge et al., 2009; Holden, 2010; McMahon \& Forehand, 2003; Moffitt et al., 2008, for reviews). Specifically, coercive processes between the parent and child emerge early in the child's development (see Granic \& Patterson, 2006; McMahon \& Forehand, 2003, for reviews) and often persist into and through adolescence (Burke, Pardini, \& Loeber, 2008). In turn, evidence-based BPT programs target these coercive family processes through a treatment approach that includes both the parent(s) and child and utilizes the following core treatment components: modeling, skill-building, and home practice. Collectively, this core of BPT treatment components are focused on increasing positive attention for appropriate child behavior, removing parental attention for inappropriate child behavior, and implementing more effective instructions and consequences for noncompliance (see Forehand, Dorsey, Jones, Long, \& McMahon, 2010; Garland, Hawley, Brookman-Frazee, \& Hurlburt, 2008; McMahon \& Forehand, 2003; Reyno \& McGrath, 2006, for reviews). Consideration of this common pool of available BPT programs is critical as it suggests that technology which successfully enhances therapist 
training in and/or service delivery of one BPT program should function similarly with other BPT programs as well.

Third, BPT for childhood DBDs has substantial research to support its efficacy. As highlighted by Chorpita and colleagues (2011, pp. 161, 163), “... the vast majority of positive findings continue to support PMT (parent management training), which also demonstrated the largest effect size..." for treatment of disruptive behaviors (note: BPT and PMT are used interchangeably; also see Chorpita et al., 2011; Dretzke et al., 2009; Eyberg et al., 2008; Kaminski, Valle, Filene, \& Boyle, 2008; Lundahl et al., 2006; McCart, Priester, Davies, \& Azen, 2006; McMahon, Wells, \& Kotler, 2006; Serketich \& Dumas, 1996, Weisz \& Gray, 2008, for reviews). Accordingly, the primary obstacles to successful intervention with families of children with DBDs is not a lack of evidence-based early intervention programs, but rather inadequate diffusion of BPT programs to therapists in real-world settings and disappointing rates of engagement and retention of families in services. Accordingly, we believe that the most important message to convey in this review is not the types of technology (i.e., "black box") that are currently being utilized in BPT, but how technology is used to overcome these two obstacles in particular (i.e., function of technology; Ritterband et al., 2009, p.22).

A final reason for focusing this review on BPT as an example for children's mental health more broadly is that the incorporation of technology, albeit in its most basic forms (i.e., videotape modeling), is firmly rooted in the history of BPT (e.g., Flanagan, Adams, \& Forehand, 1979; Nay, 1976; O'Dell et al., 1982). This review builds upon this history of technology in the field of BPT, as well as prior reviews that have highlighted the increasingly central role of technology in behavior change interventions (see Barak, Hen, Boniel-Nissim, \& Shapira, 2008; Boschen \& Casey, 2008; Clough \& Casey, 2011; Kazdin \& Blasé, 2011; Spek, et al., 2007; Wantland, Portillo, Holzemer, Saughter, \& McGhee, 2004; Tate \& Zabinski 2004, for reviews). It is important to note here, however, that prior reviews have focused primarily on interventions targeting adults, with far less attention to the role of technology in the treatment of childhood disorders, particularly disorders on the externalizing spectrum (e.g., see Graeff-Martins et al., 2008; Kazdin, 2008; Ybarra \& Eaton, 2005 , for reviews). As such, this review extends the range of solutions raised in a previous publication (Forehand \& Kotchick, 2002) by making specific recommendations for taking fuller advantage of technological innovations that are already available to consumers.

\section{Technology in BPT: Theory and Examples}

Several databases (e.g., PsycInfo; PubMed) were used to search for articles published in peer-reviewed journals over the past 20 years (i.e., unpublished dissertations were not included). A range of search terms was utilized, individually and in combination, including terms reflective of parent (e.g., caregiver, mother, childrearing), DBDs (e.g., oppositional defiant disorder, conduct disorder, behavioral disorders, externalizing disorders, disruptive behavior), intervention (e.g., skills, treatment, training, management), and platforms (e.g., mobile phones, videos, internet). Articles by authors of well-established BPT programs were also examined for reference to technology (e.g., Eyberg, Kazdin, Lochman, McMahon,

Patterson, Sanders, Webster-Stratton). Finally, additional articles were identified through the examination of the reference lists of those articles found in the initial search.

Although our search of the literature was exhaustive, our intent with the current review is not to provide details regarding every study that has incorporated technology into BPT for children. We chose to focus instead on examples of current uses of technology because, in spite of the historical roots of technology in even the earliest BPT program models (e.g., Flanagan et al., 1979; Nay, 1976; O'Dell et al., 1982), the evolution of technological 
innovations in the field is actually quite limited. For example, there are relatively few empirical investigations testing the efficacy of technology as a replacement for or enhancement to traditional therapist training models and/or treatment approaches. Furthermore, many of the articles that we identified in our search reflected multiple publications on the same BPT program and/or by the same research groups (e.g., WebsterStratton, 1982a compared the IYS group-based videotape modeling intervention to a waitlist control; Webster-Stratton, 1982b examined 1 year follow-up of families in the 1982a publication; Webster-Stratton, 1990 compared the IYS self-administered videotaped modeling intervention to a IYS group-based videotape modeling intervention). Of note, this relative dearth of empirical attention to the added value of technology in BPT, as we will discuss in detail later, is consistent with a recent review by Riley and colleagues (2011), which highlights the failure of health and services to keep pace with the advances in technology.

Part of the lag in research on technology relative to the vast potential for work in this area is a result of a relative lack of theory to guide this work (see Ritterband et al., 2009, for a review). Importantly, theory provides a framework for not only organizing the research to date, but has the potential to inform the advancement of work in this area as well. With the aim of providing a theoretical framework for organizing current work and guiding future research in BPT in particular, we turn to both models of diffusion of innovation (Rogers, 1962; 1995; 2003) and self-determination theory (Deci \& Ryan, 1985; Deci \& Ryan, 2002; Ryan \& Deci, 2000) as foundations for our review and recommendations.

Diffusion on innovation highlights the process whereby research findings come to influence practice (Rogers, 1962; 1995; 2003); however, the plethora of models aimed at unpacking the diffusion process may further complicate, rather than clarify, our understanding of how diffusion successfully occurs (e.g., Dearing, 2009; Dingfelder \& Mandell, 2011; National Institute of Health, 2009; also see Kerner \& Hall, 2009, for a review). For ease of clarity, we focus our review on two aspects of diffusion that are most relevant to BPT: (1). Increasing BPT training and supervision opportunities for therapists who work with families of children with disruptive behaviors and; (2). Engaging and retaining families of children with disruptive behaviors in BPT services when services are available

While diffusion of innovation highlights the outcomes we want to occur in BPT, selfdetermination theory provides a framework for thinking about the processes by which technology will enhance diffusion (see Williams, Lynch, \& Glasgow, 2007, for initial discussion of self-determination theory and technology). Specifically, self-determination theory considers human motivation for behavior change as falling along a continuum, which ranges from extrinsic (i.e., the propensity to engage in a particular behavior to satisfy an external requirement) to intrinsic (i.e., the tendency to engage in a behavior due to the pleasure of and interest in the behavior itself) motivation. Importantly, intrinsic motivation is considered the most likely to lead to the initiation and maintenance of behavior change because it fulfills the most basic psychological needs, including competence (i.e., need for effectiveness), relatedness (i.e., need for relationships), and autonomy (i.e., need for control). As such, self-determination theory suggests that efforts to enhance the diffusion of BPT beyond university clinics and research settings depends on the potential for the delivery vehicle to increase a sense of connectedness (i.e., relatedness) with the BPT program, therapist and skills and increase competence in the effective use of BPT skills within, but even more importantly beyond the therapy setting (i.e., autonomy). We provide specific examples below of how technology is currently utilized to reach each of these goals in the diffusion of BPT. 


\section{Harnessing Technology to Train \& Supervise Therapists in BPT}

Although it is true that some youth with DBDs receive evidence-based treatment in realworld practice settings, a building consensus notes that many, if not most, youth and their families receive substandard intervention (see Sanders et al., 2011, for a review). For example, in their study of service provision to families seeking outpatient services for disruptive behaviors, Garland and colleagues (2010) reported that several of the core components of BPT treatment were frequently utilized (e.g., using positive reinforcement); however, other core components were rarely utilized (e.g., assigning or reviewing homework, role-playing).

Why is there a discrepancy between the evidence-base for BPT and the actual services that youth with DBDs and their families receive in real-world therapy settings? Several hypotheses have been raised, including the simplest answer, which is a lack of practitioner awareness of BPT programs and their evidence base; however, the field generally agrees that far more is required than simply increasing the availability of and access to treatment manuals to practicing therapists (Chadwick Center for Children and Families, 2004; Funderburk, Ware, Altshuler, \& Chaffin, 2008). Beyond raising awareness, BPT programs must also overcome preconceived notions of manualized programs (e.g., manualized approaches limit creativity, interfere with therapist-client relations, lack relevance to real world presenting issues), particularly among those therapists who were not necessarily trained in programs that focused on evidence-based treatment (see Forehand, Merchant, Long, \& Garai, 2010; Sanders, Stallman, \& McHale, 2011, for reviews). It is unlikely that this goal can be obtained with traditional training strategies alone (e.g., one-time presentation of theory, skills demonstrations, role-playing) (e.g., Funderburk et al., 2008; Kelly et al., 2000; Van den Hombergh, Grol, Van den Hoogen, \& Van den Bosch, 1999); rather, it is more likely that ongoing opportunities for review, practice, and supervision will ensure not only fidelity to a treatment manual, but flexible use of the manual to best meet the needs of the child and family in real-world settings (Addis \& Krasnow, 2000; Addis, Wade, \& Hatgis, 1999; Garfield, 1996; Havik \& VandenBos, 1996; Kendall, Gosch, Furr, \& Sood, 2008; Sanders et al., 2011; Strupp \& Anderson, 1997; Turner, Nicolson, \& Sanders, 2011; Weisz, Sandler, Durlak, \& Anton, 2005).

Of course, such intensive training and supervision opportunities are costly for both trainers and trainees with regard to time and resources. This issue further highlights the demand for innovative and cost-effective approaches that can be tailored to best meet the specific needs of agencies and practicing clinicians (see Borrego \& Burrell, 2010; Budd, Hella, Bae, Meyerson, \& Watkin, 2011; Forehand et al., 2010; Funderburk et al., 2008; Mazzucchelli \& Sanders, 2010, for reviews). Technology, in particular, could potentially be leveraged toward the aim of cost-effective therapist training and supervision in real-world settings. It could target the central tenets posited to be associated with intrinsic motivation and successful behavior change: autonomy, support, and competence. First, technology will enhance the connection between the trainer and the therapist-in-training and the accessibility of the BPT program to the therapist, by increasing the quality of the trainer-trainee relationship and the therapist's overall positive feelings about the relevance of the BPT program for clients. In addition, technology has the potential to strengthen and build therapist competence by providing greater opportunities for feedback both during and after their sessions with regard to both flexible use of the BPT program given individual family's needs and presenting issues, as well as supervision regarding treatment fidelity. Finally, connectedness and competence will provide a foundation for therapist autonomy implement the BPT program as supervision and training are tapered and eventually end. The next section provides a few examples of the use of technology by various BPT programs to achieve these important aims. 
A very basic example of the use of technology in BPT therapist training is providing trainees with videotaped examples of expert therapists implementing the core components of BPT with parent-child dyads. Parallel to the central processes of BPT, which rely on modeling, role-play, and skills practice for parental mastery of skills and the generalization of skills from the clinic to real-world contexts (e.g., home), videos afford ongoing opportunities for therapist trainees to observe and learn from experienced BPT clinicians. Some of these videos incorporate actors playing the roles of both BPT therapist and the parent-child dyad, while others utilize clips from actual BPT sessions with families who have approved of the use of their videos for training. For example, Barkley's (1997) "Managing the Defiant Child", Eyberg and Bogg's (1998) "Parent Child Interaction Therapy" (PCIT; also see Borrego \& Burrell, 2010, for information on use of video clips), and Webster-Stratton's "Incredible Years" (IYS) Program (see Webster Stratton \& Reid, 2010, for a review) all provide a video series that illustrates therapists demonstrating critical aspects of the respective program skills with families. Perhaps most importantly, modeling by a range of expert therapists provides the opportunity for therapists-in-training to see variability in how expert therapists implement BPT skills (i.e., flexibility) while also remaining adherent to the treatment manual - a level of sophistication in the delivery of evidence-based BPT that may be easier to learn by example than in a more didactic training approach (e.g., reading an article).

One research group has taken their use of technology for therapist training and supervision a step further by utilizing "internet-based telemedicine technology," or the delivery of services remotely via the internet, as a delivery vehicle for ongoing practitioner supervision of real world community-based cases (Funderburk et al., 2008). The "telepsychology" movement is certainly not novel to children's mental health in general or to BPT in particular, yet psychology lags behind other fields in this respect (Nelson, Bui, \& Velasquez, 2011; Novotney, 2011). In fact, child psychiatry has already begun to utilize videoconferencing for the delivery of mental health services to children (e.g., Myers, Palmer, Geyer, 2011; this work will be discussed more thoroughly in a later section). An exception to the underutilization of telepsychology in BPT is the ongoing work between PCIT trainers and practitioners in the field for live, remote supervision and consultation during the provision of treatment in real-world therapy settings (see Funderburk et al., 2008, for a review). As described by Funderburk and colleagues (2008), this "remote real-time" (RRT) PCIT trainee coaching, typically coupled with telephone supervision and emails, allows the trainer to observe real-time sessions at the remote setting. During the session, the trainer can control the camera to observe various aspects of the session and can listen to and privately guide the trainee's communication with the parent and child. In turn, the trainee can also talk privately to the trainer.

Preliminary research on PCIT's RRT plus phone consultation approach suggests that clinicians rated the combined approach as more helpful overall and preferred, but less comfortable, than phone consultation alone (Funderburk et al., 2008). These results are perhaps not surprising, as the RRT approach naturally evokes at least some level of performance anxiety from even the most skilled and seasoned therapists. Nevertheless, consistent with the methods for teaching parents BPT skills (i.e., practice, feedback), RRT may not be "comfortable" but may provide a previously lacking mechanism for the delivery of BPT training from research to community settings. This may be particularly true for teaching the flexible use of BPT programs while maintaining fidelity. Therapists in training receive real-time feedback regarding the fidelity of their skill implementation and can also experiment to some extent with skill delivery in a supportive and supervised context.

A final example that we will highlight here is Webster-Stratton's IYS Program (IYS: www.incredibleyears.com), which utilizes the web to provide a central point of 
dissemination for a range of resources to professionals. These include a series of videos providing overviews of the various iterations of the IYS program, as well as video highlights of skill demonstration sessions utilized in IYS, the benefits of which we have already discussed. Other web-based resources include, but are not limited to the following: (1). Testimonials of parents who have completed the program (i.e., may increase therapist buy-in into the BPT program), didactic psychoeducation (e.g., a video series in which Dr. WebsterStratton answers frequently asked questions by group leaders about the IYS program); and (3). A "frequently-asked questions" section, which allows master IYS therapists and trainers to post and respond to questions by IYS trained clinicians. Such resources provide continued trainee support for IYS practice (i.e., relatedness) via the web while also refining the use of skills (i.e., competence) in independent practice (i.e., autonomy).

Summary-Available theoretical frameworks converge to support the potential role of technology to increase training and supervision opportunities for therapists in communitybased treatment settings and, in turn, to enhance therapist autonomy with implementing BPT programs beyond the training and supervision periods. That said, our initial review highlights that there is actually relatively little data, with the exception of preliminary findings by the PCIT group on RRT, to date to support the merits of this approach. Although we turn now to current uses of technology to overcome the second challenge to the advancement of BPT, engaging and retaining families in services, we come back to a discussion of therapist training and supervision in our recommendations for future research. We believe that the aforementioned work provides a solid foundation of research, but that there are numerous untapped opportunities to take fuller advantage of the technology available to agencies and providers to more fully extend the reach of BPT to community treatment settings.

\section{Harnessing Technology to Engage and Retain Families in BPT}

Engagement and retention are major issues in children's mental health services, and familyfocused services are no exception (see Gopalan et al., 2010; Ingoldsby, 2010; McKay \& Bannon, 2004, for reviews). Although engagement is conceptualized variably across studies (e.g., attendance vs. drop-out; early drop-out, late drop-out, \& completers; emotional investment), findings converge to highlight the critical importance of increasing parental engagement in children's mental health care. For example, Ingoldsby (2010) reported that many families receive less than one-half of the planned intervention and drop out rates can be as high as 50\%, particularly for families most in need of services (also see Fernandez, Butler, \& Eyberg, 2011). Lack of parent acceptability of the rationale for a family-focused, behavioral approach to intervention may be one reason for engagement and retention issues. This may be particularly true in the case of BPT in which the parent is a primary focus of treatment, relative to treatments for internalizing disorders in which parents often play secondary roles (see Forehand, Jones, \& Parent, in press, for a review). However, as Mah and Johnson (2008) have pointed out, parents may not engage in and complete treatment even when they do understand the rationale behind BPT and believe the approach to be acceptable for the treatment of child disruptive behavior. Accordingly, several strategies have been tested to increase parental engagement and, in turn, retention in family-focused programs, including BPT. These strategies include using group-based programs (e.g., Cunningham, Bremner, \& Boyle, 1995; McGilloway et al., 2012), home-based programs (e.g., Fernandez et al., 2011), and programs offering monetary incentives (Dumas, Begle, French, \& Pearl, 2010; Gross et al., 2011). However, findings regarding the success of such approaches are mixed at best. For example, some work suggests that group-based approaches to BPT at best may not improve (Cunningham et al., 1995) retention in BPT services and at worse may exacerbate drop-out (McGilloway et al., 2012). 
Why are the approaches tested thus far not yielding the rates of engagement we would hope for and how do we improve family engagement and retention in BPT services in particular? As highlighted by Family Stress Theory (McCubbin \& McCubbin, 1989), stressors within the family context, including a child's problem behavior, are more disruptive to family functioning than stressors that occur outside the context of the family (e.g., war, natural disaster, neighborhood violence). This is particularly true when families experience new stressors in which they have little or no experience. If we consider a diagnosis of a DBDs as a stressor for families, then learning that an evidence-based treatment is available may be an initial relief; however, as caregivers subsequently learn more detail of what is involved in treatment (e.g., treatment is focused on parenting behaviors, at least weekly clinic-based sessions, often mid-week telephone check-ins, and daily skill practice; see McMahon \& Forehand, 2003, for an example), they may feel even more burdened. This may be exacerbated for the majority of families in which only one of the child's caregivers is able to participate in BPT services due to practical considerations (e.g., other children in the home) (Cowan, Cowan, \& Berry, 2011; also see McMahon \& Forehand, 2003, for a review). The exclusion of these other caregivers, including fathers and grandmothers, who are often involved in coparenting (Choi, 2010; Gryczkowski, Jordan, \& Mercer, 2010; Jones, Zalot, Foster, Sterrett, \& Chester, 2007; McHale \& Lindahl, 2011; McMahon \& Forehand, 2003; Sanders, Dittman, Keown, Farruggia, \& Rose, 2010), increases inconsistency between parents, and decreases the likelihood that the program will lead to improvements in child behavior (McMahon \& Forehand, 2003; Wolfe, Edwards, Manion, \& Koverola, 1988). As a consequence, innovative approaches to engaging and retaining families in services must take these obstacles into account and provide strategies for overcoming them. This includes increasing the participating caregiver's support from the therapist and their coparent(s), increasing confidence in their use of new skills, and increasing their independence in using the skills in real world situations and settings. Building upon recommendations by Ingoldsby (2010) for increasing family engagement in services, the literature asserts that technology affords an innovative approach to broaden the reach of BPT services, including tailoring services for the spectrum of children with DBDs (i.e., subclinical to clinical symptomatology) and families who may benefit from these services (e.g., Long, 2004; Palmer et al., 2010; Sanders, Montgomery, \& Brechman-Toussaint, 2000). As delineated in the next two subsections, the progression of integration of technology into BPT programs has reflected the broader field of technology and health, ranging from technology used by clients with little or no therapist contact (e.g., web-based self-help programs) to technology used as an adjunct to standard face-to-face therapy practices (e.g., psychoeducation and/or support provided via mobile phones) (Boschen \& Casey, 2008; Clough \& Casey, 2011; Danaher \& Seeley, 2009; Ritterband et al., 2009; Tate \& Zabinski, 2009).

\section{Technology as the only or primary BPT intervention}

There is a long-standing tradition of self-help programming in the field of BPT, a model typically and primarily intended for families of youth with subclinical levels of disruptive behaviors (e.g., Parenting the Strong Willed Child: A Clinically Proven, Five-Week Program for Improving Your Child's Behavior, Forehand \& Long, 2010; also see Forehand et al., 2010). Accordingly, it is reasonable to think about technology as a replacement, rather than enhancement, for families of youth whose disruptive behaviors are less protracted or severe. An example of such an approach at the most basic level includes program delivery to parents via an interactive DVD series alone, such as Gordon and colleagues' "Parenting Wisely (PW): Young Children Program" (http://www.familyworksinc.com/index.html); however, we are not aware of outcome data on this program.

Another program that relies entirely, or almost entirely, on technology is the mediadelivered program central to the Level 1 Triple P Parenting Program (Triple P; Sanders, 
1999). Level 1 is a form of universal prevention that delivers psychoeducation, as well as skill-building opportunities, to parents in general, not only those parents seeking services (Sanders, 1999). Of note, relatively little of the extensive empirical research on the efficacy of the Triple P Program has focused on Level 1 relative to the more intensive levels of the program (see de Graaf, Speetjens, Smit, de Wolff, \& Tavecchio, 2008; Nowak \& Heinrichs, 2008; Sanders, 2008, for reviews). The research to date, however, suggests novel opportunities for mass dissemination of BPT messages via mass media and in particular, television (e.g., Calam, Sanders, Miller, Sadhnani, \& Carmont, 2008; Sanders, Calam, Durand, Liversidge, \& Carmont, 2008; Zubrick et al., 2005).

For example, Sanders and colleagues (2008) tested the efficacy of Triple P as a mediadelivered intervention (i.e., a primetime television series) for enhancing parenting and reducing child behavior problems. Building upon the success of reality-television, including shows like "Nanny 911", which aired both in the United States and abroad, the Triple P investigators developed at least two series, "Families" and "Driving Mum and Dad Mad" (e.g., Calam et al., 2008; Sanders et al., 2008; Sanders, 2008). Although there are different versions of the weekly series, in general, it features the experience of multiple families with young children who are enrolled in the group version of the Triple P Program.

In addition to the television series, viewers also have access to sources of information about disruptive behaviors and behavioral parent training skills through other types of technology, including a website with program materials and information. Findings from this research demonstrated the important role technology can play in media-delivered BPT. Children's disruptive behaviors and parenting practices improved at post-intervention and follow-up (Calam et al., 2008; Sanders et al., 2008). In addition to work by PW and Triple P, WebsterStratton and colleagues tested a self-administered version of IYS, which relies heavily on videotape modeling of skills for families (see Webster-Stratton, 1982, for a review), as well as a web-based version that is supplemented with professional consultation via email, phone calls, and home visits (Taylor et al., 2008). We will consider the newer web-delivered program first. This version of IYS includes videos of parent-child interactions, as well as other relevant program material (e.g., sound files with pre-recorded group question and answer sessions, text summary of key points). We are not aware of a study that compares this program to the standard IYS program or to a control group; yet, results of within-group research revealed a relatively high retention rate $(76 \%)$, as well as a high degree of achievement of family goals and family satisfaction with the program (Taylor et al., 2008).

The non-web delivered, self-administered IYS program has a much longer history and relies on videotapes. These videotapes provide information and examples of skill practice and demonstrations, as well as supplementary workbooks with short readings, case vignettes, and skill practice assignments (see Webster-Stratton, 1981a; 1981b, for initial descriptions of the role of videotape modeling). Several studies suggest promising improvements immediately post-treatment and at follow-up assessments spanning as long as one year. These improvements were observed in parenting and child behavior for families randomized to the individually self-administered videotape modeling treatment relative to a waitlist control group. The findings were particularly evident with nonclinical samples (e.g., Webster-Stratton, 1982a; 1982b; 1992). The individually self-administered IYS videotape modeling treatment yielded less favorable outcomes compared to the standard IYS groupdiscussion videotape modeling treatment, which is facilitated by a therapist (e.g., WebsterStratton, 1990; Webster-Stratton, 1992; Webster-Stratton, Kolpakoff, \& Hollinsworth, 1988). These findings are perhaps not surprising as more symptomatic populations may require at least some level of therapist involvement. Accordingly, we now turn our attention to technology as an enhancement to traditional BPT treatment models. 


\section{Technology-Enhancements to Standard Face-to-Face BPT Programs}

While the aforementioned findings highlight the opportunity for technology to broaden the reach of BPT programs to caregivers more directly, research suggests that more intensive therapist involvement may still be necessary for those families whose children are experiencing clinically significant disruptive behaviors and/or families experiencing other concomitant social, economic, familial, or psychological stressors. (e.g., de Graaf et al., 2008; Hanisch et al., 2010; Lyon \& Budd, 2010; Nowak \& Heinrichs, 2008; Sanders, 2008; also see Weisz et al., 2005). With this caveat mind, technology provides the opportunity to enhance therapist-delivered BPT and potentially reduce therapist and client burden (e.g., fewer sessions required to reach therapeutic goals). Some of these technology-enhancements have a long-standing history in the field of BPT, while others represent more recent technological innovations.

We highlighted the role of videos as a mechanism for BPT skill modeling in the prior section; however, utilizing videos to maximize modeling opportunities has a longstanding tradition in more clinic-based BPT approaches as well (e.g., Flanagan, Adams, \& Forehand, 1979; O’Dell et al., 1982; Webster-Stratton, 1994). The opportunity to view videos of parenting skills demonstrations in session and/or in the home between therapy sessions can provide multiple benefits to the participating caregiver. For example, it exposes the participating caregiver to the correct practice of the target skills, prompts for skill practice, and increases the opportunity for non-participating caregivers to become involved in skill practice as well.

As one example of using video modeling, Nixon and colleagues (2003) compared an abbreviated version of PCIT to the standard protocol. The abbreviated version consisted of only 5 (instead of the typical 12) sessions and videos. The videos included psychoeducation and demonstrations of parenting skills for families to watch at home. Findings indicated that the abbreviated format was equally effective to the standard 12-session protocol, suggesting that video modeling can reduce the number of sessions necessary for successful BPT.

Another long-standing use of technology to enhance traditional BPT programs is the use of technology to connect with and support families practicing new BPT skills between face-toface sessions (Webster-Stratton, 1990). For example, McMahon and Forehand's (2003) HNC program includes regular mid-week calls between sessions as a primary component of the intervention. More recent innovations in technology afford therapists an increased range of opportunities to connect with families between sessions utilizing not only telephone contacts, but electronic messaging (e.g., email, text messages, and even chat rooms or twitter messaging for group-based programs) and videoconferencing (e.g., two-way cameras in many smartphones, skype) (de Graaf et al., 2008; Markie-Dadds \& Sanders, 2006; Morawska \& Sanders, 2006; Nixon, Sweeney, Erikson, \& Touyz, 2003; Nowak \& Heinrichs, 2008; Sanders, 2008; Sanders, Markie-Dadds, Tully, \& Bor, 2000).

Although we are not aware of data that examine the added-value of utilizing technology to connect with and support families between sessions, likely benefits include providing an opportunity for parents to check in during the week regarding their progress with skills, obstacles to practice, and/or concerns about their use of the skills or their child's response. In turn, therapists have the potential to learn critical information about the family's homebased practice (or lack thereof), provide directive feedback to the family to guide remaining practices prior to the next session, and increase family motivation and investment in the BPT skill-building process. For example, we recently conducted a pilot randomized control trial (RCT) that examined whether smartphone technology increased engagement and therapeutic outcomes of low-income families enrolled in HNC (Jones, Forehand, Cuellar, Parent, Khavou, Honeycutt, Gonzalez, \& Anton, manuscript in preparation; also see Jones, 
Forehand, McKee, Cuellar, \& Kincaid, 2010, for a review). During a mid-week videoconferencing call with one family enrolled in the study, the mother used the two-way camera feature to walk the therapist through the family's house in order to identify the ideal place for implementing time-out at home. If she had not received guidance on this issue, the mother may have forfeited the practice of time-out altogether until the next session or incorrectly placed the time-out chair in a place not free from distraction, decreasing the potential effectiveness of the procedure.

Technology has also been used in other ways to increase the opportunity for feedback to families enrolled in traditional BPT programs. For example, Phaneuf and McIntyre (2007) tested the effect of adding individualized video feedback to a group-based IYS program (Webster-Stratton \& Reid, 2010) for mothers of children with developmental disabilities, whom the authors highlight are at increased risk for disruptive behaviors. Findings from the multiple baseline design revealed that videotaping mother-child dyads, watching the videos with mothers, and providing feedback regarding inappropriate maternal behavior was more effective than the intervention without videotaped feedback.

Although not a traditional BPT program, Van Zeijl and colleagues (2006) tested their attachment-based intervention, "Video-Feedback Intervention to Promote Positive Parenting and Sensitive Discipline" (VIPP-SD), with families of youth at-risk for disruptive behaviors. During the course of the program, parent-child interactions are videotaped in the home, the therapist reviews the videos between sessions, and then the therapist and parent discuss portions of the videos during the next session. Caregivers are reinforced for the use of new skills and receive constructive feedback from the therapist. Findings revealed that families in the VIPP-SD intervention, relative to those in the control condition (telephone consultation only), improved in parenting and child behavior problems. One can only imagine the breadth of possibilities for such an approach for BPT programs. For example, in our pilot RCT with low-income families (Jones et al., 2010), parents videotaped at least one home practice per week and reviewed it with the therapist at the beginning of the next session. The therapist provided both positive and constructive feedback. The parent's skill level on the video also informed the therapist about the starting point for skill-building in the session.

\section{Summary}

As highlighted in the prior two subsections, technology has been utilized to both directly connect families of children with disruptive behaviors to BPT programs as well as to enhance the delivery of more traditional clinic-based BPT program models. Although the research is not extensive in either area, our examples highlight the potential for technology to improve BPT to better meet the needs of children and families. Accordingly, the next section will discuss recommendations for future research directions to advance in BPT through technological innovations.

\section{Harnessing Innovations in Technology to Advance BPT: Future Research Directions}

Thus far, we have highlighted the specific research-to-practice challenges associated with BPT programming and provided examples of technologies that are currently being utilized by state-of-the-field BPT programs. With the aim of further advancing the field of BPT and its reach to providers and families, we now turn our attention to specific research questions that merit consideration as we harness innovations in technology to advance training and treatment opportunities. 


\section{Do New Technologies Offer New Opportunities to Overcome the Challenges of BPT?}

If we do not keep pace with the innovations in technology, we may miss opportunities for technology to help us overcome the primary challenges facing the field of BPT. By investigating new technologies within the context of BPT, we will hopefully achieve our primary aims of increasing the reach of BPT to therapists via training and supervision opportunities and enhancing the engagement and retention of families in services. With these goals in mind, we consider how new technologies may afford innovative strategies for increasing relationship and skill (competence) building, as well as autonomy in skill utilization, the aforementioned critical ingredients of behavior change when training therapists and teaching BPT skills to families. For example, there are a myriad of opportunities to increase the information exchange between developers of BPT programs and the therapists and families that they intend to serve. Such opportunities include podcasts, which are being utilized in other health services research approach (Turner-McGrievy et al., 2009), as well as audiobooks. Podcasts could provide information to a broad audience of parents on the following topics: the link between parental responses to child disruptive behavior and the perpetuation of the behavioral problems of children; the rationale behind BPT; and an overview of parenting skills. Such an approach may increase parental interest in and commitment to participating in a BPT intervention. Toward a similar end, WebsterStratton developed an audiobook DVD set for caregivers, "The Incredible Years: A Guide for Parents of Children 2-8 Years Old" in both English and Spanish Versions (http:// www.incredibleyears.com); however, we are not aware of outcome data demonstrating the impact of listening to the audiobook alone on parenting behavior or child outcomes.

In addition, BPT has not taken advantage of the rise in "applications" or "apps" that can be utilized via a multitude of interfaces (e.g., smartphones, computers). They have the potential to deliver meaningful information, as well as skill demonstrations. For example, a cursory review of the Apple "App Store" reveals a myriad of applications for time-out that allow the user to enter the child's name and birthdate or age and the application provides a time-out timer. As has been argued before (Jones et al., 2010), however, keeping track of the time is unlikely to be the most challenging part of time-out for the vast majority of parents. Thus, there is room for more interactive and useful BPT applications for teaching (e.g., where to place the time-out chair, how to get a child into time-out) and problem solving issues (e.g., what to do when a child refuses to remain in the time-out chair) around the use of time-out (and other parenting skills).

We have emphasized the importance of modeling skills in BPT throughout this review; new technologies afford the capability to provide more realistic modeling and skill practice opportunities for parents than have traditionally occurred. One example of a platform that could be used is virtual reality. Building upon the increased use of virtual reality in the assessment and treatment of childhood disruptive behavior disorders (see Withrow, Has, \& Holten, 2011, for a review) and other problems (see David, 2010, for a review), virtual technologies could be helpful for caregivers in BPT as well. For example, the use of virtual technology may facilitate a connection between the use of skills in session and the use of skills in contexts beyond the therapy setting and home where parents may need to utilize their new BPT skills. For example, caregivers may have difficultly dealing with child disruptive behaviors when shopping (e.g., temper tantrum when told "no" regarding the sugar cereal), in the car (e.g., unbuckling the seat belt, climbing over the front seat), and at playgrounds (e.g., hitting other children). Although utilization of the BPT skills in these settings can be practiced via role play with the child in the session, role plays fail to compare with the reality of the frustration, fear, and even embarrassment that caregivers feel when they have difficulty controlling their child's behavior in public. Virtual reality, in turn, has the untapped potential to provide caregivers with far more realistic scenarios typically 
experienced by families of youth with DBDSs, as well as therapist coaching and support in effectively utilizing BPT skills in these scenarios.

Thus far in this section we have focused our examples on engaging and retaining families; however, we believe that the same strategies could be utilized to increase training and supervision opportunities for therapists as well. Although RRT (remote real time) coaching provides a yet unparalleled opportunity for training in BPT,Funderburk et al. (2008) acknowledge the costs of setting up and maintaining such a sophisticated videoconferencing system, which may be prohibitive for many community settings. That said, advances in technology afford a range of possibilities for creating similar training and supervision opportunities that may lack some of the sophistication afforded by RRT and similar systems, but would function similarly. For example, computers, notebook computers, and other handheld technologies, including smartphones, provide accessibility to the web. In turn, web access allows for various modes of real-time communication, including videoconferencing, as well as access to email, chat rooms, and social networking sites (Aguilera \& Muench, 2012). Such resources have the potential to provide trainers a window into ongoing BPT sessions conducted by trainees and, in turn, allow remote supervision and training opportunities. They could also serve as forums for support and information exchange. These opportunities will help build the relationship between trainer and trainee, promote trainee skill building (competence), and enhance therapist autonomy.

\section{Can Technology be Utilized to Deliver BPT to the Most Vulnerable Children \& Families?}

Kazak and colleagues (2010) have noted that in children's mental health, "treatments that work are often not provided to those who would benefit the most from them" (p. 86) and BPT is no exception. Specifically, as highlighted by Gardner, Connell, Trentacosa, Shaw, Dishion and Wilson (2009), "Parenting interventions in general are less successful at engaging the most distressed and disadvantaged families" (p. 545). Although this conclusion is equally applicable to other intervention approaches, the primary point is that BPT is doing a substandard job of engaging and retaining low-income families (see Lundahl et al., 2006, for a review).

Consistent with the theoretical frameworks discussed earlier, Family Stress Theory highlights the indirect impact of financial strain on children through parental stress and compromises in parenting (Conger \& Elder, 1994; Conger et al., 2002). Accordingly, it is not surprising that low-income families are more vulnerable to the coercive cycle of parentchild interaction implicated in the development and exacerbation of DBDS (e.g., Dodge et al., 2009; McMahon \& Forehand, 2003; Moffitt et al., 2008). Moreover, financial strain and associated difficulties in making ends meet decrease the probability that weekly meetings with a therapist can or will take priority (see Reyno \& McGrath, 2006, for a review). For example, a recent pilot of the PCIT program delivered in a community mental health setting to lower income families reported that of the 14 families referred for services, 12 families initiated treatment and only four of these families finished the program (Lyon \& Budd, 2010).

Can technology help to engage, retain, and successfully treat low income families enrolled in BPT? We believe the answer is "yes". For example, these families are the most likely to "cut the cord" on landlines and more likely than other groups to rely entirely on mobile phones (Snider, 2011). Smartphones, in particular, provide lower income consumers with previously unattainable access to a range of technologies (e.g., videos, internet, telephone, videoconferencing etc) at a fraction of the prior cost associated with the purchase of multiple devices to obtain the same options (Jones et al., 2010; Lawson, 2008). Such trends, in turn, support our assertion that technology may offer an unparalleled opportunity to reach these highest risk families. Consistent with our prior assertion that delivery of BPT through 
technology alone is best in the least complicated cases, smartphones would ideally supplement more traditional BPT with these families. However, providing BPT only through technology may be more effective than no treatment with high-risk families.

Another technology-driven approach to reach high-risk families, particularly those living in remote or rural areas, is "telemental health" through which services are delivered remotely to clients. For example,Palmer et al. (2010) are conducting the first federally funded randomized control trial to compare the efficacy of a "telemental health" model to treatment in a more typical primary-care setting for 6-to-12 year old children with attention deficit hyperactivity disorder (ADHD). Although ADHD may differ from DBDs due to its chronicity (see Pelham \& Fabiano, 2008, for a review), evidence to suggest efficacy for such an approach with ADHD may inform the field regarding potential opportunities to utilize this strategy with BPT for DBDs as well. Of note, several states, including Louisiana, Michigan, South Carolina, and Texas, are using a teleconferencing model to increase the delivery of services to youth and families (Dubin, 2010), highlighting the critical need for more research to inform service-delivery in this area. These efforts begin to lay the foundation for offering child behavioral interventions, including BPT, remotely to low income, disadvantaged families.

\section{Is Technology a Cost-Effective Approach to Advancing BPT?}

The cost-effectiveness of standard BPT programs, including IYS, PCIT, and Triple P, have been examined elsewhere (see Cunningham, Bremner, \& Boyle, 1995; Foster, Prinz, Sanders, \& Shapiro, 2008; Lee et al., 2012; Mihalopoulos, Sanders, Turner, Murphy, Brennan, \& Carter, 2007; O'Neil et al., 2011; Sanders, 2008, for reviews). For example, cost-effectiveness analyses by Lee and colleagues (2012) revealed monetary benefits for our society from the implementation of PCIT ranging from $\$ 4$ (reduction in repeating grades $\mathrm{K}-12)$ to $\$ 2,583$ (reduction in health care costs for disruptive behavior symptoms). That said, far less research attention has been devoted to the cost-effectiveness of enhancing or replacing standard BPT programs with technology (Jones, Forehand, Cuellar, Parent, Khavou, Honeycutt, Gonzalez, \& Anton, manuscript in preparation), which is reflective of the broader telehealth and telepsychology fields as well. For example, Tate, Finkelstein, Khavjou, and Gustafson (2009) highlight that although cost-effectiveness is given as a primary rationale for developing service-based internet interventions, only 8 of the 420 studies published on internet interventions from 1995 to 2008 reported economic indicators. Of these, the authors noted that "many were lacking comprehensive analyses" (Tate et al., 2009, p. 40), leaving relatively little to be said regarding cost-effectiveness.

Thus, there is a unique opportunity to examine the incremental cost-effectiveness afforded by the integration of technology into BPT training and programs. This examination could provide data used to guide policy-makers and funding sources with increasingly limited mental health resources. One framework to guide such work identifies "sunk costs" for technology-delivered or technology-enhanced BPT programs as the costs to develop the intervention, such as programming and licensing (Tate et al., 2009, p. 43). These are costs that would occur for the researchers developing the technology and not recur for the agencies, providers, and families using them. The greater cost of delivery for the real-world users (i.e., therapists \& families) would be the cost of the "black box" (i.e., the computer, smartphone, tablet notebook), as well as its maintenance (e.g., data plans on smartphones). These costs certainly cannot be minimized; however, many of the suggestions we offered in the aforementioned sections could be delivered through technologies that an increasing number of families, including low-income families, will already own (e.g., smartphones). In turn, this has the potential to reduce the cost to providers and/or families. 
With regard to provider training, whether agencies could afford to provide access to technology-driven training opportunities is a research question in and of itself. However, the upfront cost of investing in the technology that would allow training and supervision is probably minimal relative to the expense of therapists traveling to training workshops (e.g., gas, food, lodging), as well as taking time off from work (e.g., not generating income through providing services) for the training. Although the aforementioned remote real-time (RRT) training model is likely relatively expensive to set-up and maintain (Funderburk et al., 2008), many of the other options that we discussed (e.g., computers, notebook computers, and smartphones have internet and, in turn, videoconferencing capabilities) may be more reasonable investments.

\section{What are the Ethical Issues Related to Technology in BPT Programs?}

As with other aspects of the use of technology in services research, the field is progressing far more quickly than advances in relevant ethical guidelines (Novotney, 2011; also see Reed, McLaughlin, \& Milholland, 2000; Richardson et al., 2009). In fact, leaders in the field highlight that "the tail is wagging the dog in some ways on this issue" (Novotney, 2011, p. 40), as advances in technology far outpace the rate at which practice guidelines are updated to deal with new challenges. Some of the potential ethical issues related to any telehealth approach include cross-state licensure (e.g., therapist supervising another therapist or conducting therapy with a patient in another state), standard-of-care (e.g., emergency protocols when a client is not physically in the same room as the provider or there is no "provider"), privacy and security (e.g., use of secure networks, encryption of emails, confidentiality in group chat rooms), and feasibility (e.g., training both therapists and clients in the use of technology).

The field of BPT is not immune from any of these ethical issues. For example, if a BPT trainer is supervising a therapist's case remotely via some type of videoconferencing connection, what security measures need to be in place to guarantee a family's confidentiality? How does the therapist in training assess a family's understanding of the remote supervision and its implications for the broader range of providers who may be involved in their case? Who regulates the technology to ensure that it is being utilized in a manner that maximizes the security of data and images obtained from remotely observed sessions?

Similarly complicated issues arise when we think about families interfacing directly with technology. A prime example is the issue of child maltreatment. Even in a model that relies entirely on face-to-face services, sensitive issues like child maltreatment can be difficult for the most experienced BPT therapists to navigate (see McMahon \& Forehand, 2003, for a review). And, these issues only increase when we consider relying on technology delivered services. For example, how will the potential for child maltreatment be assessed via technology? Will an increased reliance on technology increase the probability that signs of abuse will be overlooked or missed? Finally, will opportunities to report abuse, thus protecting a child, be reduced in technology-driven BPT interventions? Would this issue be more salient for those technology-driven interventions that substantially decrease or replace the provider and, in turn, lose the value added by trained clinical assessment and judgment?

\section{Summary}

Building upon the examples of how technology is currently being utilized in BPT, we have highlighted opportunities to move the field even further by beginning to outline a research agenda, including the following: 1). Increase the extent to which we look to new technologies in order to increase our functional capabilities to reach therapists and families; 2). Utilize technology to better meet the needs of underserved children and families, 
including low-income families; 3). Examine the cost-effectiveness of the integration of technology into BPT; and 4). Advance ethical decision-making and guidelines regarding the use of technology in the treatment of DBDs.

We will make one more recommendation here as well. That is, regardless of which "black box" (e.g., smartphone, computer) is utilized by BPT researchers and therapists or the intended functions provided by the "black box", far more attention is warranted to studies that examine the added-value of the technology to BPT training satisfaction and program outcomes for therapists and families (also see Riley et al., 2011, for a review). That is, is it the case that therapists who participate in technology-driven or enhanced training and supervision are as satisfied with the experience as those therapists who participate in person? If there is some loss of satisfaction associated with the use of technology, is it minimal enough to warrant such an approach anyway if the incorporation of technology dramatically increases therapist training/supervision opportunities and is cost-effective, thereby moving BPT programs from research and university training clinics to real world practice settings? Similarly, does the incorporation of technology into BPT programs enhance parenting and child behavior outcomes beyond what we would expect given outcomes for the standard BPT program and/or are the outcomes similar but obtained more efficiently (e.g., fewer inperson sessions for technology-enhanced programs) and, in turn, with greater costeffectiveness than standard face-to-face delivery only?

These are only a few of the important questions that need to be addressed as we, like other subfields in health and mental health, continue to look to technology to increase the reach and impact of our service delivery and enhance training opportunities. Throughout this review, we have purposefully utilized quotes (e.g., "the tail wagging the dog") highlighting that innovations in technology are far outpacing our integration of technology into services research. That said, we also think it is critical that technology only be integrated once it is tested utilizing our gold-standard research designs. This will ensure that the field is, in fact, moving forward to best meeting the needs of those who will deliver our interventions and parents who will utilize them to treat their children. In short, we need a data-driven approach, rather than being persuaded by the bells and whistles of new "black boxes".

\section{Conclusions}

Although BPT is an evidence-based intervention with a large database supporting its efficacy, significant challenges compromise successful diffusion from university research clinics to real-world service delivery settings. Specifically, increasing training and supervision opportunities for therapists on the front lines of treatment and engaging and retaining the families that they are charged with serving are obstacles hindering advancement of the field. We believe technology is one approach for addressing these challenges, although empirical support for such an approach is limited. Thus, our hope is that this review will not only provide information about the current state-of-the-field, but it will also provide a theoretical and empirical foundation to advance the literature in this area.

In turn, just as BPT will certainly borrow examples of uses of technology from other subfields, we hope that the use of technology with BPT to treat child DBDs could also stimulate research on technology in the treatment of other childhood disorders. As we noted earlier, practicality and cost-effectiveness of technology depends in large part on the generalizability of approaches tested from one BPT program for DBDs to another; however, we also believe such approaches should be generalizable to evidence-based treatments for other childhood disorders as well. For example, several of the core components of BPT (e.g., positive attention for prosocial behavior, modeling of skills, homework practice and review) are also typical strategies utilized in evidence-based approaches for other externalizing 
disorders (e.g., ADHD), as well as some approaches to treating internalizing disorders (e.g., anxiety; see Forehand et al., in press). Such overlap with regard to common components of evidence-based treatment appraoches suggests that technological innovations should function similarly regardless of childhood disorder.

\section{Acknowledgments}

Funding for this project was provided to by NIMH (1R34MH082956; ClinicalTrials.gov Identifier: NCT01367847). We wish to acknowledge Joel Sherrill, Program Chief, Child and Adolescent Psychosocial Intervention Program, for his guidance on our own project related to technology and BPT; our colleagues at Research Triangle International, Amanda Honeycutt and Olga Khavjou, for their contributions to our understanding of costeffectiveness analyses; and Greg Newey, Research Technology Solutions, for his guidance and assistance with our understanding of how to maximize technology to advance the field of BPT. Additional support for this project was provided by NICHD (RO1HD064723).

\section{References}

Addis ME, Krasnow AD. A national survey of practicing psychologists' attitudes toward psychotherapy treatment manuals. Journal Of Consulting And Clinical Psychology. 2000; 68(2): 331-339. [PubMed: 10780134]

Addis ME, Wade WA, Hatgis C. Barriers to dissemination of evidence-based practices: Addressing practitioners' concerns about manual-based psychotherapies. Clinical Psychology: Science And Practice. 1999; 6(4):430-441.

Aguilera A, Muench F. There's an App for that: Information technology applications for cognitive behavioral practitioners. the Behavior Therapist. 2012; 35:65-73.

Anderson P, Jacobs CH, Lindner GK, Edwards S, Zimand E, Hodges L, Rothbaum BO. Cognitive behavior therapy for fear of flying: Sustainability of treatment gains after September 11. Behavior Therapy. 2006; 37:91-97. [PubMed: 16942964]

Barak A, Hen L, Boniel-Nissim M, Shapira N. A comprehensive review and a meta-analysis of the effectiveness of internet-based psychotherapeutic interventions. Journal of Technology in Human Services. 2008; 26(2-4):109-160.

Barkley, RA. Managing the defiant child. New York: Guilford Publications, Kevin Dawkins, Producer; 1997.

Belfer ML, Saxena S. WHO child atlas project. The Lancet. 2006; 367(9510):551-552.

Borrego J, Burrell TL. Using behavioral parent training to treat disruptive behavior disorders in young children: A how-to approach using video clips. Cognitive and Behavioral Practice. 2010; 17:25-34.

Boschen MJ, Casey LM. The use of mobile telephones as adjuncts to cognitive behavioral psychotherapy. Professional Psychology: Research and Practice. 2008; 39:546-552.

Budd KS, Hella B, Bae H, Meyerson DA, Watkin SC. Delivering parentchild interaction therapy in an urban community clinic. Cognitive and Behavioral Practice. 2011; 18:502-514.

Burke JD, Pardini DA, Loeber R. Reciprocal relationships between parenting behavior and disruptive psychopathology from childhood through adolescence. Journal of Abnormal Child Psychology. 2008; 36(5):679-692. [PubMed: 18286366]

Burns BJ, Hogwood K, Mrazek PJ. Effective treatment for mental disorders in children and adolescents. Clinical Child and Family Psychology Review. 1999; 2(4):199-254. [PubMed: 11225935]

Calam R, Sanders M, Miller C, Sadhnani V, Carmont SA. Can technology and the media help reduce dysfunctional parenting and increase engagement with preventive parenting interventions. Child Maltreatment. 2008; 13:347-361. [PubMed: 18641169]

Chadwick Center on Children and Families. Closing the quality chasm in child abuse treatment: Identifying and disseminating best practices. San Diego, CA: Author; 2004.

Choi J. Nonresident fathers' parenting, family processes, and children' s development in urban, poor, single-mother families. Social Service Review. 2010; 84(4):655-677. [PubMed: 21488323] 
Chorpita BF, Daleiden EL, Ebesutani C, Young J, Becker KD, Nakamura BJ, Starace N. Evidencebased treatments for children and adolescents: An updated review of indicators of efficacy and effectiveness. Clinical Psychology: Science and Practice. 2011; 18(2):154-172.

Clough BA, Casey LM. Technological adjuncts to increase adherence to therapy: A review. Clinical Psychology Review. 2011; 31:697-710. [PubMed: 21497153]

Conger, R.; Elder, GH. Families in troubled times: Adapting to change in rural America. Aldine de Gruyter; 1994.

Conger RD, Wallace LE, Sun Y, Simons RL, McLoyd VC, Brody GH. Economic pressure in African American families: a replication and extension of the family stress model. Developmental psychology. 2002; 38(2):179. [PubMed: 11881755]

Costello EJ, Foley DL, Angold A. 10-year research update review: The epidemiology of child and adolescent psychiatric disorders: II. developmental epidemiology. Journal of the American Academy of Child \& Adolescent Psychiatry. 2006; 45:825.

Cowan CP, Cowan PA, Barry J. Couples' groups for parents of preschoolers: Ten-year outcomes of a randomized trial. Journal of Family Psychology. 2011; 25:240-250. [PubMed: 21480703]

Cunningham CE, Bremner R, Boyle M. Large group community-based parenting programs for families of preschoolers at risk for disruptive behaviour disorders: Utilization, cost effectiveness, and outcome. Journal of Child Psychology and Psychiatry. 1995; 36:1141-1159. [PubMed: 8847377]

Danaher BG, Seeley JR. Methodological issues in research on web-based behavioral interventions. Annals of Behavioral Medicine. 2009; 38(1):28-39. [PubMed: 19806416]

David D. Cutting edge developments in psychology: Virtual reality applications interview with two leading experts. Journal of Cognitive and Behavioral Psychotherapies. 2010; 10:115-125.

Dearing JW. Applying diffusion of innovation theory to intervention development. Research on Social Work Practice. 2009; 19:503-518. [PubMed: 20976022]

Deci, EL.; Ryan, RM. Intrinsic motivation and self-determination in human behavior. New York: Plenum; 1985.

Deci, EL.; Ryan, RM., editors. Handbook of self-determination theory research. Rochester, NY: Rochester University Press; 2002.

de Graaf I, Speetjens P, Smit F, de Wolff M, Tavecchio L. Effectiveness of the Triple P Positive Parenting Program on Parenting: A meta-analysis. Family Relations. 2008; 57:553-566.

Dingfelder HE, Mandell DS. Bridging the research to practice gap in autism intervention: An application of diffusion of innovation theory. Journal of Autism \& Developmental Disorders. 2011; 41:597-609. [PubMed: 20717714]

Dodge KA, Malone PS, Lansford JE, Miller S, Pettit S, Bates JE. A dynamic cascade model of the development of substance-use onset. Monographs of the Society for Research in Child Development. 2009; 74:1-31.

Dretzke J, Davenport C, Frew E, Barlow J, Stewart-Brown S, Bayliss S, Hyde C. The clinical effectiveness of different parenting programmes for children with conduct problems: A systematic review of randomized controlled trials. Child and Adolescent Psychiatry and Mental Health. 2009; 3

Dubin, JW. Hello! Your psychiatrist will skype you now. 2010. http://www.time.come/time/health/ article/0,8599,1974196,00.html

Dumas JE, Begle A, French B, Pearl A. Effects of monetary incentives on engagement in the PACE parenting program. Journal Of Clinical Child And Adolescent Psychology. 2010; 39(3):302-313. [PubMed: 20419572]

Egger HL, Angold A. Common emotional and behavioral disorders in preschool children: Presentation, nosology, and epidemiology. Journal of Child Psychology and Psychiatry. 2006; 47:313-337. [PubMed: 16492262]

Eyberg, SM.; Boggs, SR. Parent-child interaction therapy: A psychosocial intervention for the treatment of young conduct-disordered children. In: Briesmeister, JM.; Schaefer, CE.; Briesmeister, JM.; Schaefer, CE., editors. Handbook of parent training: Parents as co-therapists for children's behavior problems. 2nd ed.. Hoboken, NJ US: John Wiley \& Sons Inc.; 1998. p. 61-97. 
Eyberg SM, Nelson MM, Boggs SR. Evidence-based psychosocial treatments for children and adolescents with disruptive behavior. Journal of Clinical Child and Adolescent Psychology. 2008; 37(1):215-237. [PubMed: 18444059]

Fernandez MA, Butler AM, Eyberg SM. Treatment outcome for low socioeconomic status African American families in parent-child interaction therapy: A pilot study. Child \& Family Behavior Therapy. 2011; 33:32-48.

Flanagan S, Adams HE, Forehand R. A comparison of four instructional techniques for teaching parents to use time-out. Behavior Therapy. 1979; 10(1):94-102.

Fleitlich B, Goodman R. Social factors associated with child mental health problems in Brazil: Cross sectional survey. BMJ: British Medical Journal. 2001; 323:599-600.

Forehand R, Dorsey S, Jones DJ, Long N, McMahon RJ. Adherence and flexibility: They can (and do) exist. Clinical Psychology: Science and Practice. 2010; 17:258-264.

Forehand R, Jones DJ, Parent J. Behavioral parent-training for child disruptive behaviors and anxiety: What's different and what's the same? Clinical Psychology Review. (in press).

Forehand R, Kotchick BA. Behavioral parent training: Current challenges and potential solutions. Journal of Child and Family Studies. 2002; 11:377-384.

Forehand R, Merchant MJ, Long N, Garai E. An examination of parenting the strong-willed child as bibliotherapy for parents. Behavior Modification. 2010; 34:57-76. [PubMed: 20051525]

Forehand R, Merchant MJ, Parent J, Long N, Linnea K, Baer J. An examination of a group curriculum for parents of young children with disruptive behavior. Behavior Modification. 2011; 35:235-251. [PubMed: 21478243]

Foster E, Prinz RJ, Sanders MR, Shapiro CJ. The costs of a public health infrastructure for delivering parenting and family support. Children and Youth Services Review. 2008; 30:493-501.

Funderburk BW, Ware LM, Altshuler E, Chaffin M. Use and feasibility of telemedicine technology in the dissemination of parent-child interaction therapy. Child Maltreatment. 2008; 13:377-382. [PubMed: 18843144]

Galbraith JS, Stanton B, Boekeloo B, King W, Desmond S, Howard D, Carney JW. Exploring implementation and fidelity of evidence-based behavioral interventions for HIV prevention: Lessons learned from the focus on kids diffusion case study. Health Education \& Behavior. 2009; 36:532-549. [PubMed: 18445739]

Gardner F, Connell A, Trentacosta CJ, Shaw DS, Dishion TJ, Wilson MN. Moderators of outcome in a brief family-centered intervention for preventing early problem behavior. Journal of Consulting and Clinical Psychology. 2009; 77:543-553. [PubMed: 19485594]

Garfield SL. Some problems associated with 'validated' forms of psychotherapy. Clinical Psychology: Science And Practice. 1996; 3(3):218-229.

Garland AF, Brookman-Frazee L, Hurlburt MS, Accurso EC, Zoffness RJ, Haine-Schlagel R, Ganger W. Mental health care for children with disruptive behavior problems: A view inside therapists' offices. Psychiatric Services. 2010; 61:788-795. [PubMed: 20675837]

Garland AF, Hawley KM, Brookman-Fraze L, Hurlburt MS. Identifying common elements of evidence-based psychosocial treatments for children's disruptive behavior problems. Journal of the Academy of Child and Adolescent Psychiatry. 2008; 47:505-514.

Gopalan G, Goldstein L, Klingenstein K, Sicher C, Blake MMC, McKay MM. Engaging families into child mental health treatment: Updates and special considerations. Journal of the Canadian Academy of Child and Adolescent Psychiatry. 2010; 19:182-196. [PubMed: 20842273]

Gordon DA. Parent training via CDROM: Using technology to disseminate effective preventive interventions. The Journal of Primary Prevention. 2000; 21:227-251.

Graeff-Martins AS, Flament MF, Fayyad J, Tyano S, Jensen P, Rohde LA. Diffusion of efficacious interventions for children and adolescents with mental health problems. Journal of Child Psychology and Psychiatry. 2008; 49:335-352. [PubMed: 18333931]

Granic I, Patterson GR. Toward a comprehensive model of antisocial development: A dynamic systems approach. Psychological Review. 2006; 113:101-131. [PubMed: 16478303]

Gross D, Julion W, Fogg L. What motivates participation and dropout among lowincome urban families of color in a preventive intervention? Family Relations. 2001; 50:246-254. 
Gryczkowski MR, Jordan SS, Mercer SH. Differential relations between mothers' and fathers' parenting practices and child externalizing behavior. Journal of Child and Family Studies. 2010; 19:539-546.

Hanisch C, Freund-Braier I, Hautmann C, Jänen N, Plück J, Brix G, Döpfner M. Detecting effects of the indicated Prevention Programme for Externalizing Problem Behaviour (PEP) on child symptoms, parenting, and parental quality of life in a randomized controlled trial. Behavioural and Cognitive Psychotherapy. 2010; 38:95-112. [PubMed: 19995467]

Havik OE, VandenBos GR. Limitations of manualized psychotherapy for everyday practice. Clinical Psychology: Science And Practice. 1996; 3(3):264-267.

Holden, GW. Parenting: A dynamic perspective. Thousand Oaks, CA US: Sage Publications, Inc.; 2010.

Ingoldsby EM. Review of interventions to improve family engagement and retention in parent and child mental health programs. Journal of Child and Family Studies. 2010; 19:629-645. [PubMed: 20823946]

Jones DJ, Forehand R, McKee L, Cuellar J, Kincaid C. Behavioral parent training: Is there an 'app' for that? the Behavior Therapist. 2010; 33:72-77. [PubMed: 22199418]

Jones DJ, Zalot A, Foster S, Sterrett E, Chester C. A review of childrearing in African American single mother families: The relevance of a coparenting framework. Journal of Child and Family Studies. 2007; 16:671-683.

Kaminski JW, Valle LA, Filene JH, Boyle CL. A meta-analytic review of components associated with parent training program effectiveness. Journal of Abnormal Child Psychology. 2008; 36:567-589. [PubMed: 18205039]

Kazak AE, Hoagwood K, Weisz JR, Hood K, Kratochwill TR, Vargas LA, Banez GA. A meta-systems approach to evidence-based practice for children and adolescents. American Psychologist. 2010; 65(2):85-97. [PubMed: 20141264]

Kazdin, AE. The Kazdin method for parenting the defiant child. Boston: Houghton Mifflin; 2008.

Kazdin AE, Blasé SL. Rebooting psychotherapy research and practice to reduce the burden of mental illness. Perspectives on Psychological Science. 2011; 6:21-37.

Kelly JF, Buehlman K, Caldwell K. Training personnel to promote quality parent-child interaction in families who are homeless. Topics in Early Childhood Special Education. 2000; 20:174-185.

Kendall PC, Gosch E, Furr JM, Sood E. Flexibility within fidelity. Journal of the American Academy of Child \& Adolescent Psychiatry. 2008; 47(9):987-993. [PubMed: 18714195]

Kerner JF, Hall KL. Research dissemination and diffusion: Translation with science and society. Research on Social Work Practice. 2009; 19:519-530.

Lawson, S. Low-income Users Latch on to IPhone. 2008. Retrieved from http://www.pcworld.com/

Lee, S.; Aos, S.; Drake, E.; Pennucci, A.; Miller, M.; Anderson, L. Return on investment: Evidencebased options to improve statewide outcomes, April 2012 (Document No. 12-04-1201). Olympia: Washington State Institute for Public Policy; 2012.

Long N. Editorial: Are we doing enough for children? Clinical Child Psychology and Psychiatry. 2004; 9(2):163-165.

Lundahl B, Risser HJ, Lovejoy MC. A meta-analysis of parent training: Moderators and follow-up effects. Clinical Psychology Review. 2006; 26:86-104. [PubMed: 16280191]

Lyon AR, Budd KS. A community mental health implementation of Parent-Child Interaction Therapy (PCIT). Journal of Child and Family Studies. 2010; 19:654-668. [PubMed: 20877583]

Mah JWT, Johnston C. Parental social cognitions: Considerations in the acceptability of and engagement in behavioral parent training. Clinical Child and Family Psychology Review. 2008; 11:218-236. [PubMed: 18836832]

Marikangas KR, Nakamura EF, Kessler R. Epidemiology of mental disorders in children and adolescents. Dialogues in Clinical Neuroscience. 2009; 11:7-20. [PubMed: 19432384]

Markie-Dadds C, Sanders MR. A controlled evaluation of an enhanced selfdirected behavioral family intervention for parents of children with conduct problems in rural and remote areas. Behaviour Change. 2006; 23:55-72. 
Mazzucchelli TG, Sanders MR. Facilitating practitioner flexibility within an empirically supported intervention: Lessons from a system of parenting support. Clinical Psychology: Science and Practice. 2010; 17:238-252.

McCart MR, Priester PE, Davies WH, Azen R. Differential effectiveness of behavioral parent-training and cognitive-behavioral therapy for antisocial youth: A metaanalysis. Journal of Abnormal Child Psychology. 2006; 34:527-543. [PubMed: 16838122]

McCubbin, MA.; McCubbin, HI. Theoretical orientations to family stress and coping. In: Figley, CR., editor. Treating stress in families. New York: Brunner/Mazel; 1989. p. 3-43.

McGilloway S, Mhaille GN, Bywater T, Furlong M, Leckey Y, Kelly P, Cominskey C. A parenting intervention for childhood behavioral problems: A randomized controlled trial in disadvantaged community-based settings. Journal of Consulting and Clinical Psychology. 2012; 80:116-127. [PubMed: 22148879]

McHale, J.; Lindahl, K., editors. Coparenting: A conceptual and clinical examination of family systems. Washington, DC US: American Psychological Association; 2011.

McKay MM, Bannon WM. Engaging families in child mental health services. Child and Adolescent Psychiatry Clinics of North America. 2004; 13:905-921.

McKleroy VS, Galbraith JS, Cummings B, Jones P, Harshbarger C, Collins C, . Carney JW. Adapting evidence-based behavioral interventions for new settings and target populations. AIDS Education and Prevention. 2006; 18 59-59-73.

McLoyd VC. Socioeconomic disadvantage and child development. American Psychologist. 1998; 53:185-204. [PubMed: 9491747]

McMahon, RJ.; Forehand, RL. Helping the noncompliant child: Family-based treatment for oppositional behavior. New York: Guilford Press; 2003.

McMahon, RJ.; Wells, KC.; Kotler, JS. Conduct problems. In: Mash, EJ.; Barkley, RA., editors. Treatment of childhood disorders. 3rd ed.. New York: Guilford Press; 2006. p. 137-268.

Mihalopoulos C, Sanders MR, Turner KMT, Murphy-Brennan M, Carter R. Does the Triple P Positive Parenting Program provide value for money? Australian and New Zealand Journal of Psychiatry. 2007; 41:239-246. [PubMed: 17464705]

Moffitt TE, Arseneault L, Jaffee SR, Kim-Cohen J, Koenen KC, Odgers CL, Viding E. Research review: DSM-V conduct disorder: Research needs for an evidence base. Journal of Child Psychology and Psychiatry. 2008; 49:3-33. [PubMed: 18181878]

Morawska A, Sanders MR. Self-administered behavioral family intervention for parents of toddlers: Effectiveness and dissemination. Behaviour Research and Therapy. 2006; 44:1839-1848. [PubMed: 16458853]

Myers KM, Palmer NB, Geyer JR. Research in child and adolescent telemental health. Child and Adolescent Psychiatric Clinics of North America. 2011; 20:155-171. [PubMed: 21092919]

National Advisory Mental Health Council. A Report by the National Advisory Mental Health Council's Workgroup on Child and Adolescent Mental Health Intervention Development and Deployment. Bethesda, MD: National Institutes of Health/National Institute of Mental Health; 2001. Blueprint for Change: Research on Child and Adolescent Mental Health.

National Institute of Health. Dissemination and implementation research in health (R01). 2009. http:// grants.nih.gov/grants/guide/pa.files/PAR-07-086.html

Nay, W. Behavioral intervention: Contemporary strategies. Oxford England: Gardner Press; 1976.

Nelson EL, Bui TN, Velasquez SE. Telepsychology: Research and practice overview. Child and Adolescent Psychatric Clinics of North America. 2011; 20:67-79.

Nixon RD, Sweeney L, Erikson DB, Touyz SW. Parent-Child Interaction Therapy: A comparison of standard and abbreviated treatments for oppositional defiant preschoolers. Journal of Consulting and Clinical Psychology. 2003; 71:251-260. [PubMed: 12699020]

Novotney A. A new emphasis on telehealth: How can psychologists stay ahead of the curve - and keep patients safe? Monitor on Psychology. 2011 Jun.:40-45.

Nowak C, Heinrichs N. A comprehensive meta-analysis of Triple P Positive Parenting Program using hierachical linear modeling: Effectiveness and moderating variables. Clinical Child and Family Psychology Review. 2008; 11:114-144. [PubMed: 18509758] 
O'Dell S, O'Quin J, Alford B, O'Briant A, Bradlyn A, Giebenhain J. Predicting the acquisition of parenting skills via four training models. Behavior Therapy. 1982; 13:194-208.

O'Neill D, McGilloway S, Donnelly M, Bywater T, Kelly P. A cost-effectiveness analysis of the incredible years parenting programme in reducing childhood health inequalities. The European Journal of Health Economics. 2011

Palmer NB, Myers KM, Vander Stoep A, McCarty CA, Geyer JR, Desalvo A. Attention-deficit/ hyperactivity disorder and telemental health. Current Psychiatry Report. 2010; 5:409-417.

Pelham WE, Fabiano GA. Evidence-based psychosocial treatments for attentiondeficit/ hyperactivity disorder. Journal of Clinical Child and Adolescent Psychology. 2008; 37:184-214. [PubMed: 18444058]

Phaneuf L, McIntyre LL. Effects of individualized video feedback combined with group parent training on inappropriate maternal behavior. Journal of Applied behavior Analysis. 2007; 40:737-741. [PubMed: 18189109]

Reed GM, McLaughlin CH, Milholland K. Ten interdisciplinary principles for professional practice in telehealth: Implications for psychology. Professional Psychology: Research \& Practice. 2000; 31:170-178.

Reyno SM, McGrath PJ. Predictors of parent training efficacy for child externalizing behavior problem--a meta-analytic review. Journal of Child Psychology and Psychiatry. 2006; 47:99-111. [PubMed: 16405646]

Richardson LK, Frueh BC, Grubaugh AL, Johnston RH, Egede L, Johnson RH, Elhai JD. Current directions in videoconferencing tele-mental health research. Clinical Psychology: Research \& Practice. 2009; 16:323-338.

Riley WT, Schumann MF, Forman-Hoffman VL, Mihm P, Applegate BW, Asif O. Responses of practicing psychologists to a web site developed to promote empirically supported treatments. Professional Psychology: Research And Practice. 2007; 38(1):44-53.

Ritterband LM, Thorndike FP, Cox DJ, Kovatchev BP, Gonder-Frederick LA. A behavior change model for internet interventions. Annals of Behavioral Medicine. 2009; 38:18-27. [PubMed: 19802647]

Rogers EM. How research can improve practice: A case study. Theory into Practice. 1962; 1(2):89-93. Rogers, EM. Diffusion of innovations. Simon and Schuster; 1995.

Rogers, M. Knowledge, technological catch-up and economic growth. Edward Elgar Publishing; 2003.

Ryan RM, Deci EL. Self-determination theory and the facilitation of intrinsic motivation, social development, and well-being. American Psychologist. 2000; 55:68-78. [PubMed: 11392867]

Sanders MR. Triple P-Positive Parenting Program: Towards an empirically validated multilevel parenting and family support strategy for the prevention of behavior and emotional problems in children. Clinical Child and Family Psychology Review. 1999; 2:71-90. [PubMed: 11225933]

Sanders MR. Triple P Positive Parenting Program as a public health approach to strengthening parenting. Journal of Family Psychology. 2008; 22:506-517. [PubMed: 18729665]

Sanders M, Calam R, Durand M, Liversidge T, Carmont SA. Does self-directed and web-based support for parents enhance the effects of viewing a reality television series based on the Triple $\mathrm{P}$ Positive Parenting Program? Journal of Child Psychology and Psychiatry. 2008; 49:924-932. [PubMed: 18492040]

Sanders MR, Dittman CK, Keown LJ, Farruggia S, Rose D. What are the parenting experiences of fathers? The use of household survey data to inform decisions about the delivery of evidencebased parenting interventions to fathers. Child Psychiatry and Human Development. 2010; 41:562-581. [PubMed: 20449648]

Sanders MR, Markie-Dadds C, Tully LA. The Triple P-Positive Parenting Program: A comparison of enhanced, standard, and self-directed behavioral family intervention for parents of children with early onset conduct problems. Journal of Consulting and Clinical Psychology. 2000; 68:624-640. [PubMed: 10965638]

Sanders MR, Montgomery DT, Brechman-Toussaint M. The mass media and the prevention of child behavior problems: The evaluation of a television series to promote positive outcome for parents and their children. Journal of Child Psychology and Psychiatry. 2000; 41:939-948. [PubMed: 11079436] 
Sanders MR, Stallman HM, McHale M. Workplace Triple P: A controlled evaluation of a parenting intervention for working parents. Journal of Family Psychology. 2011; 25:581-590. [PubMed: 21728418]

Serketich WJ, Dumas JE. The effectiveness of behavioral parent training to modify antisocial behavior in children: A meta-analysis. Behavior Therapy. 1996; 27:171-186.

Snider, M. A quarter of American homes have hung up on landlines. 2011. http://www.usatoday.com/ tech/news/2011-04-20-cellphone-study.htm

Spek V, Cuijpers P, Nyklíček I, Riper H, Keyzer J, Pop V. Internet-based cognitive behaviour therapy for symptoms of depression and anxiety: A meta-analysis. Psychological Medicine: A Journal of Research in Psychiatry and the Allied Sciences. 2007; 37:319-328.

Strupp HH, Anderson T. On the limitations of therapy manuals. Clinical Psychology: Science And Practice. 1997; 4(1):76-82.

Tate DF, Finkelstein EA, Khavjou O, Gustafson A. Cost effectiveness of internet interventions: Review and recommendations. Annals of Behavioral Medicine. 2009; 38:40-45. [PubMed: 19834778]

Tate DF, Zabinski MF. Computer and internet applications for psychological treatment: Update for clinicians. Journal of Clinical Psychology. 2004; 60:209-220. [PubMed: 14724928]

Taylor TK, Webster-Stratton C, Feil EG, Broadbent B, Widdop CS, Severson HH. Computer-based intervention with coaching: An example using the Incredible Years program. Cognitive Behaviour Therapy. 2008; 37:233-246. [PubMed: 18803072]

Turner KM, Nicholson JM, Sanders MR. The role of practitioner self-efficacy, training, program and workplace factors on the implementation of an evidence-based intervention in primary care. Journal of Primary Prevention. 2011; 32:95-112. [PubMed: 21451942]

Turner-McGreivy GM, Campbell MK, Tate DF, Truesdale KP, Bowling M, Crosby L. Pounds off digitally: A randomized podcasting weight-loss intervention. American Journal of Preventive Medicine. 2009; 37:263-269. [PubMed: 19765496]

Van den Hombergh P, Grol R, Van den Hoogen HJ, Van den Bosch WJ. Practice visits as a tool in quality improvement: acceptance and feasibility. Quality \& Safety in Health Care. 1999; 8:167171.

Van Zeijl J, Mesman J, Van IJzendoorn, Bakermans-Kranenburg M, Juffer F, Stolk MN, . Alink LR. Attachment-based intervention for enhancing sensitive discipline in mothers of 1- to 3-year-old children at risk for externalizing behavior problems: A randomized controlled trial. Journal of Consulting and Clinical Psychology. 2006; 74:994-1005. [PubMed: 17154730]

Wantland DJ, Portillo CJ, Holzemer WL, Slaughter R, McGhee EM. The effectiveness of web-based vs. non-web-based interventions: A meta-analysis of behavioral change outcomes. Journal of Medical Internet Research. 2004; 6:e40. [PubMed: 15631964]

Webster-Stratton C. Teaching mothers through videotape modeling to change their children's behavior. Journal of Pediatric Psychology. 1982; 7(3):279-294. [PubMed: 7131215]

Webster-Stratton C. The long-term effects of a videotape modeling parent-training program: Comparison of immediate and 1-year follow-up results. Behavior Therapy. 1982; 13(5):702-714.

Webster-Stratton C. Randomized trial of two parent-training programs for families with conductdisordered children. Journal of Consulting and Clinical Psychology. 1984; 52:666-678. [PubMed: 6470293]

Webster-Stratton C. Enhancing the effectiveness of self-administered videotape parent training for families with conduct-problem children. Journal of Abnormal Child Psychology. 1990; 18:479492. [PubMed: 2266221]

Webster-Stratton C. Individually administered videotape parent training: 'Who benefits?'. Cognitive Therapy and Research. 1992; 16:31-52.

Webster-Stratton C. Advancing videotape parent training: A comparison study. Journal of Consulting and Clinical Psychology. 1994; 62:583-593. [PubMed: 8063985]

Webster-Stratton, C. Early intervention with videotape modeling: Programs for families of children with oppositional defiant disorder or conduct disorder. In: Hibbs, ED.; Jensen, PS.; Hibbs, ED.; Jensen, PS., editors. Psychosocial treatments for child and adolescent disorders: Empirically 
based strategies for clinical practice. Washington, DC: American Psychological Association; 1996. p. 435-474.

Webster-Stratton, C. Oppositional-defiant and conduct-disordered children. In: Hersen, M.; Ammerman, RT., editors. Advanced abnormal child psychology. 2nd ed.. Mahwah, NJ: Lawrence Erlbaum Associates Publishers; 2000. p. 387-412.

Webster-Stratton C, Hammond M. Conduct problems and level of social competence in Head Start children: Prevalence, pervasiveness, and associated risk factors. Clinical Child and Family Psychology Review. 1998; 1:101-124. [PubMed: 11324301]

Webster-Stratton C, Hollinsworth T, Kolpacoff M. The long-term effectiveness and clinical significance of three cost-effective training programs for families with conductproblem children. Journal of Consulting and Clinical Psychology. 1989; 57:550-553. [PubMed: 2504794]

Webster-Stratton C, Kolpacoff M, Hollinsworth T. Self-administered videotape therapy for families with conduct-problem children: Comparison with two cost-effective treatments and a control group. Journal of Consulting and Clinical Psychology. 1988; 56:558-566. [PubMed: 3143750]

Webster-Stratton, C.; Reid, MJ. The Incredible Years parents, teachers, and children training series: A multifaceted treatment approach for young children with conduct disorders. In: Weisz, J.; Kazdin, A., editors. Evidence-based psychotherapies for children and adolescents. 2nd ed.. New York: Guilford Publications; 2010. p. 194-210.

Weisz JR, Gray JS. Evidence-based psychotherapy for children and adolescents: Data from the present and a model for the future. Child and Adolescent Mental Health. 2008; 13:54-65.

Weisz JR, Sandler IN, Durlak JA, Anton BS. Promoting and protecting youth mental health through evidence-based prevention and treatment. American Psychologist. 2005; 60:628-648. [PubMed: 16173895]

Williams GC, Lynch M, Glasgow RE. Computer-assisted intervention improves patient-centered diabetes care by increasing autonomy support. Health Psychology. 2007; 26:728-734. [PubMed: 18020845]

Withrow LM, Hash PAK, Holten KB. Managing ADHD in children: Are you doing enough? Medication, monitoring, and regular evaluation remain the mainstay of treatment for this disorder, but there are nuances (and new developments) you need to know. The Journal of Family Practice. 2011; 60:E1-3. [PubMed: 21472144]

World Health Organization. The World Health Report - Mental Health: New Understanding, New Hope. 2001. Retrieved from: http://www.who.int/whr/2001/en/

Wolfe DA, Edwards B, Manion I, Kaveorola C. Early intervention for parents at risk of child abuse and neglect: A preliminary investigation. Journal of Consulting and Clinical Psychology. 1988; 56:40-47. [PubMed: 3346447]

Ybarra ML, Eaton WW. Internet-based mental health interventions. Mental Health Services Research. 2005; 7:75-87. [PubMed: 15974154]

Zisser, A.; Eyberg, SM. Parent-child interaction therapy and the treatment of disruptive behavior disorders. In: Weisz, JR.; Kazdin, AE., editors. Evidence-based psychotherapies for children and adolescents. New York: Guilford; 2010. p. 179-193.

Zubrick SR, Ward KA, Silburn SR, Lawrence D, Williams AA, Blair E, Sanders MR. Prevention of child behavior problems through universal implementation of a group behavioral family intervention. Prevention Science. 2005; 6:287-304. [PubMed: 16160760] 